\title{
FIELD RESEARCH AND CONSERVATION
}

\author{
INSTRUCTORS $\downarrow$ CHUCK COLLIS $\downarrow$ KATIE STORMS \\ CLAYTON HIGH SCHOOL $\uparrow$ CLAYTON, MO
}

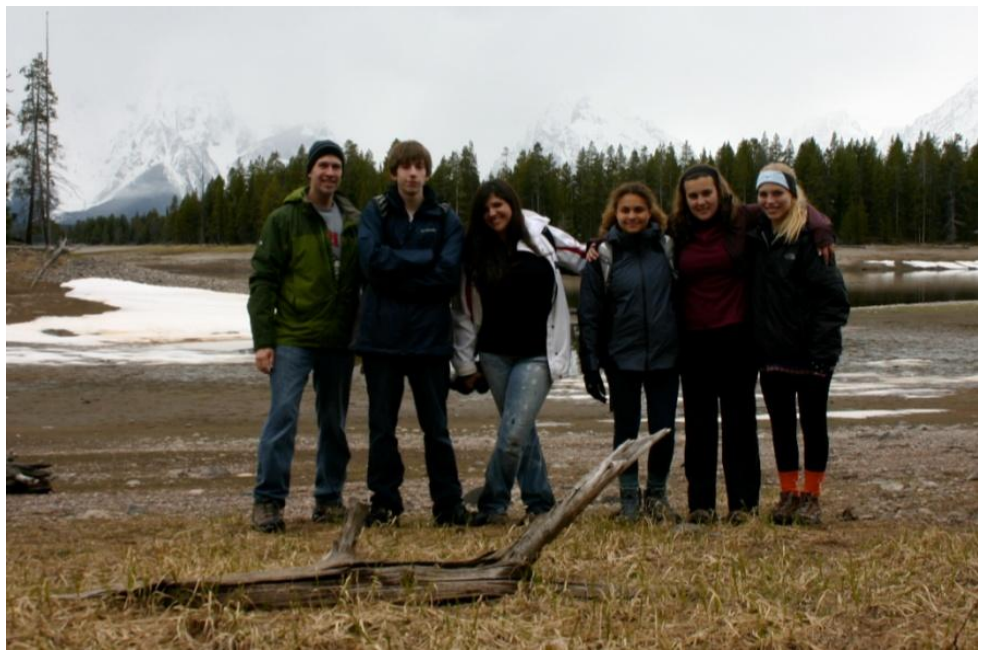

Figure 1. Students and Instructors

\section{$\uparrow \quad$ Class OVERVIEW}

Field Research \& Conservation emphasizes long-term field research experiences, examines ecosystem processes, and explores the evolution of American perspectives about nature.

A group of four students was selected from numerous applicants to serve as research assistants to Dr. Scott Sakaluk. During our two week stay at the AMK, our primary objective was to perform a markrecapture study to estimate the sagebrush cricket (Cyphoderris strepitans) population at Dead Man's Bar. We determined that the male population is 914 $+/-333$ individuals (95\% confidence interval).

Our secondary research objective was to gather preliminary data pertaining to female receptiveness to male nuptial gift behaviors when the females are held on different diets. Our hypothesis was that females on poor diets (apple only) would be more receptive to calling males than females held on an ad libitum diet consisting of apple, pollen, and cat food. Although the sample size was too low for a complete study, the results indicate that this investigation may deserve additional research: 3 of 4 females in the poor diet group mounted a male while only 1 of 5 females in the rich diet group mounted a male.

Living within a community of research scientists had tremendous benefits to my students. On numerous occasions we conversed with researchers about their work and gained valuable insights concerning the design and implementation of scientific studies. Dr. J. Chad Johnson stands out in particular in this regard because we were able to discuss his research over dinner a number of times and also work with him in the field and lab.

Aside from conducting research, we explored Grand Teton and Yellowstone National parks to learn about ecosystem dynamics, the role of disturbance and succession, and the influences of geologic process in shaping landscapes and the communities that occupy them. 

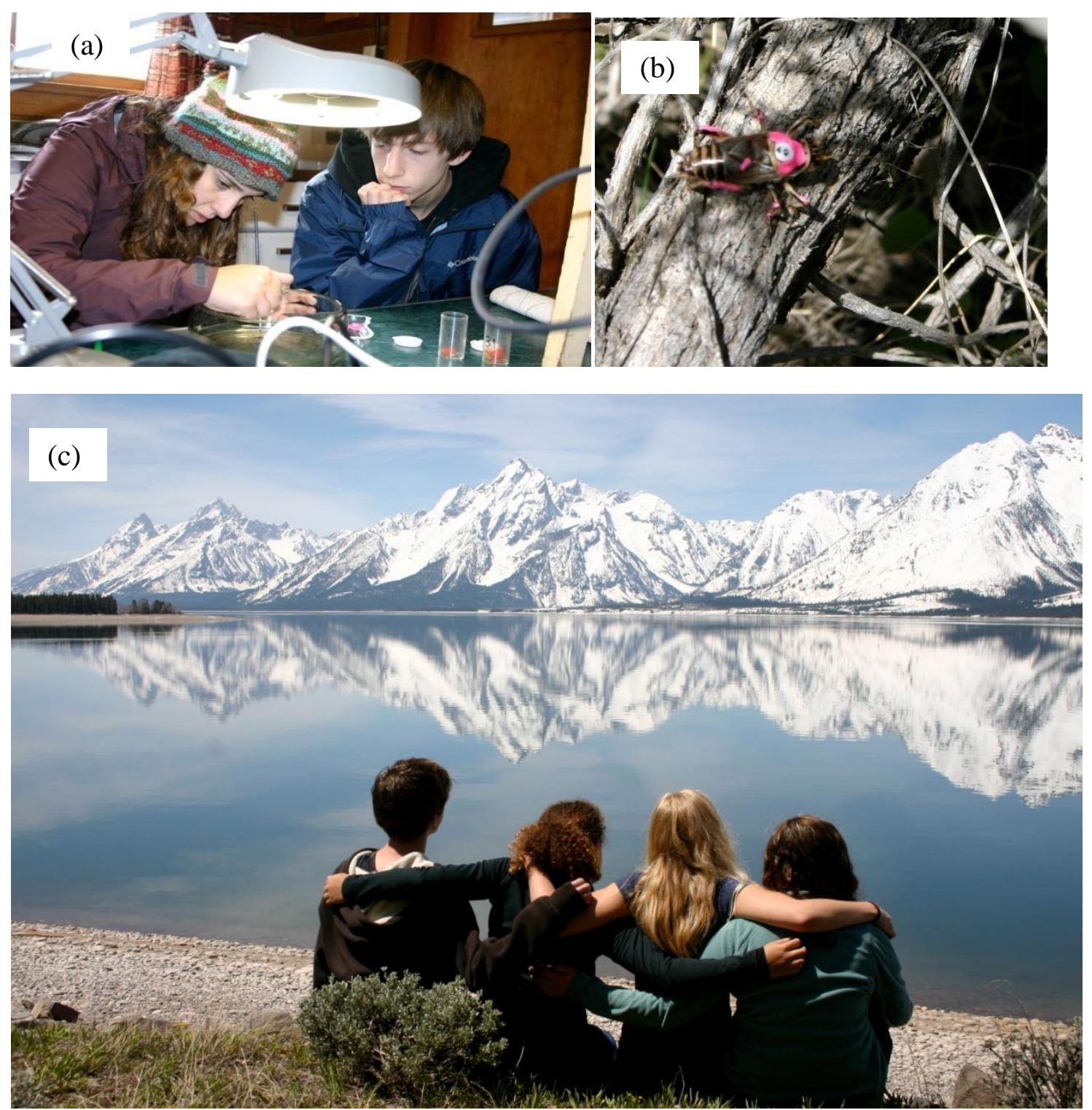

Figure 2. (a) Students applying identification markers to captured sage cricket, (b) Marked sage cricket released to its capture site, (c) Students admiring view from the AMK Ranch shoreline. 